\title{
Feasibility Study of Small Scale Battery Storage Systems Integrated with Renewable Generation Technologies for Sri Lankan Domestic Applications
}

\author{
Wattala Fernando, Naren Gupta, Givaki Kamyab \\ School of Engineering and the Built Environment \\ Edinburgh Napier University, Merchiston Campus, \\ 10 Colinton Road \\ Edinburgh, EH105DT \\ w.fernando@napier.ac.uk
}

\begin{abstract}
The purpose of energy storage technologies is to ultimately increase the efficiency of renewable energy generation methods and systems and decrease global $\mathrm{CO}_{2}$ emissions, thus tackling the sustainability targets of the Sri Lanka government. This research aims to provide a summary of energy storage and to determine the feasibility and optimal battery storage technology for a 3-bedroom house when integrated with a renewable generation source such as solar photovoltaic (PV). This research was carried out by using a renewable energy system analysis tool called HOMER pro. Solar PV system was modelled and simulated with alternative types of battery; lithium ion and lead-acid batteries, in grid-connected mode. To get a better understanding of how the battery storage could be utilized, it was trailed in Matara, located on the south coast of Sri Lanka.
\end{abstract}

Index Terms-- Renewable energy, Sri Lanka, Sustainability, Incineration, Municipal Solid Waste.

\section{INTRODUCTION}

Ongoing concerns about climate change, the adverse environmental and social backlashes over fossil fuel consumption (such as air pollution or deaths related to the industry) and the finite nature of fossil fuels, have been voiced over a few centuries but have been mostly overlooked. However, these concerns were taken more seriously in the 1970s, mainly due to the "oil crisis" which led to a steep rise in oil prices, and the fear of security of supply arose [12]. Started in 1995, the United Nations has convened a series of annual meet up climate change conferences. The meeting in 1997 in Kyoto, Japan, agreed the "Kyoto Protocol". Under this agreement, countries were expected to tackle climate change by reducing greenhouse gas emission by $6-8 \%$ below their 1990 levels and predict where this could be reached by 2012 [12].

Climate change, global warming and security of supply for energy are the primary motivations for countries investing in renewable energy technologies [8] and that utilize renewable

\author{
C Ozveren Suheyl
}

\author{
School of Science Engineering and Technology \\ Abertay University, \\ 40 Bell Street, \\ Dundee, DD1 1HG,
}

resources, for green electricity generation. Most countries have begun investing in variable renewables phase out fossil fuels and not to depend on them as heavily.

Therefore, with an increasing effort to begin planning to reduce the need for fossil fuels and begin to de-carbonize the energy sector, action was taken in November 2016 at the United Nations Climate Change Conference. During that summit, 176 out of 197 parties signed the agreement to protect the climate and undertake ambitious efforts to deal with the climate change effects caused by countries. [15]

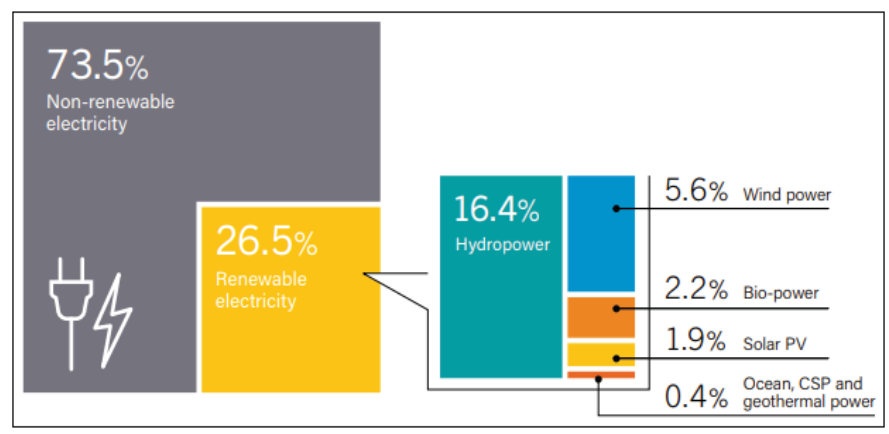

Figure 1 The renewable energy share of global electricity production 2017.

Globally, the most promising renewable resources for alternative electricity production are wind, biomass and solar energy after hydroelectricity. Figure 1 illustrates the renewable energy share of global electricity production in 2017. Wind and solar technologies have shown the most significant increase over the last decade. Between 2016 and 2017 alone, global installed capacity for solar energy grew from 303 to $402 \mathrm{GW}$ and wind energy grew from 487-539 GW [13]. Despite this, as seen below in Figure 1, wind and solar energies combined only contributed around $7.5 \%$ of the total global electricity production [13] in comparison to the current $73.5 \%$ from fossil fuels energy consisting of coal, oil and gas. 
However, wind and solar energy are viable options for our future energy needs; they have relatively low carbon footprints in terms of grams of $\mathrm{CO}_{2}$ per $\mathrm{kWh}$ of electrical energy produced. Moreover, they are considered environmentally friendly sources of electricity generation compared to fossil fuel burning [11] as seen in Table 1 .

TABLE 1 COMPARISON BETWEEN VARIOUS TECHNOLOGIES IN TERMS OF THEIR CARBON FOOTPRINT

\begin{tabular}{|c|c|}
\hline Technology/fuel & Mean estimate $\left(\mathbf{g C O}_{\mathbf{2}} \mathbf{e} / \mathbf{k W h}\right)$ \\
\hline Solar Photovoltaic & 50 \\
\hline Wind & 34 \\
\hline Natural Gas & 492 \\
\hline Coal & 960 \\
\hline
\end{tabular}

However, despite renewables being a clean source of electricity generation, they bring other issues. High penetration of wind and solar are causing concern to power network systems due to the variability, intermittency and reverse power flows associated with them [10]

To ensure the reliability of renewable sources, many efforts have been made to ensure that the power network remains stable and reliable. The researched methods include battery storage, load shifting through demand management and interconnection with external grids. However, amongst all of these, battery storage is recognized as one of the most promising options available [7]

Utilizing a renewable source such as wind or solar is difficult, as the resource can't be turned on and off like traditional thermal power stations that use fossil fuels, where the fuel can be stored easily. We need to use the electricity when the resource is available which may not meet daily demand variations.

Small-scale renewable generation technologies such as micro wind turbines, solar PV panels integrated with energy storage such as a rechargeable battery can provide a reliable supply of electricity to a commercial building or domestic dwelling. Thus, batteries can be used to store electricity during the day when the resource is available. When the dwelling is occupied in the evening time, the battery is discharged to meet demand, therefore overcoming the intermittency issues of the renewable source.

\section{ENERGY STORAGE}

\section{A Background}

Energy functionality requires energy in the form that is needed, at the right place, at the right time. Facilitating this requires some energy storage. Currently, energy and power generation methods are going through a transition from a fossil fuel - ruled energy sector to more sustainable sources consisting of renewable energy technologies [2]. Energy storage allows for separation of energy production from consumption, therefore decreasing the need to continue monitoring and predict the consumer's peak demand spikes, as shown in Figure 2 [14].

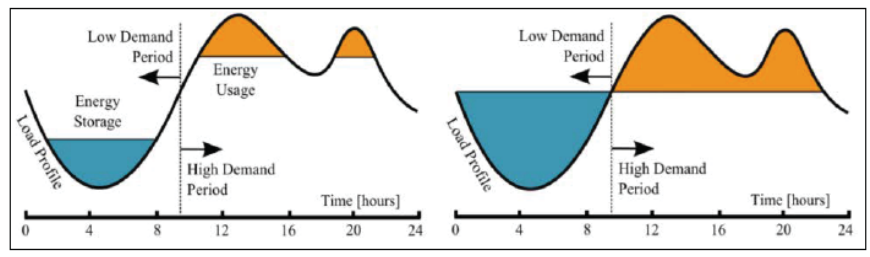

Figure 2 Domestic energy demand profile over 24 period

Motivated by the need to displace baseload power stations, there has been much focus and research given towards energy storage in recent years, as more renewables are connected to the grid network [3]. It is vital that energy storage becomes the norm in energy systems, as renewables don't always provide power when needed. Therefore, a building would still depend on fossil fuels for power, even if solar PV or a micro wind turbine were to be installed. Hence, storage is critical in allowing this unused energy to be stored as chemical energy and then be used when needed by consumers for electrical devices. Therefore, the energy that would have been wasted, from the renewable technologies, can be used when the resource is not available through energy storage.

\section{$B$ Advantages of Energy Storage}

Battery storage has a wide range of electrical applications, from on-grid connections to off-grid systems. The benefits associated with storage include balancing the variable characteristics of renewable energy, providing back-up power such as frequency and voltage stability [1]; therefore, ensuring reliable energy supply and allowing a higher increase in the penetration of renewable energy technologies on an electrical network. Another advantage of battery storage is "peak shaving". This is where demand is reduced through lowering the demand profile and reducing peaks within the profile, which results in a smoother and stable supply [10].

Other advantages of energy storage include autonomous systems, transmission support, spinning reserve, transient stability and load levelling [9]. Battery storage can be easily scaled from small batteries at the consumers' end, to large battery systems that can smooth out the power output from wind farms that have intermittence issues due to the nature of the resource.

There is also an economic benefit in having storage within a building; the battery can be charged from the grid at night time when electricity prices are low and then used during the day when electricity prices are higher.

\section{Disadvantages of Energy Storage}

The most significant drawback for battery storage systems is the high capital costs associated with them, although prices are falling due to the uptake in electric vehicles, namely the lithium-ion battery. Moreover, another disadvantage mentioned by [6] is that batteries have lower energy densities than fossil fuels. Furthermore, it is stated that additional energy is required in the first place to build and construct a new battery system, which has embodied energy. Therefore, this could make the renewable energy systems for off-grid applications unfeasible. 
In addition, batteries introduce a new environmental problem associated with them, such as toxic waste from individual batteries that contain cadmium and nickel that are used for the chemical reactions that take place within the battery. People and companies are hesitant to begin investing right now due to the anticipation of advances in other scientific and technological fields required for some energy storage technologies to develop.

Another disadvantage to energy storage, if lithium-ion batteries are used as the preferred battery, is identified in an article written by [4]. It states that at the current expected rate of mining lithium-ion, for electric vehicles and storage systems, it is estimated that there is only around 50 years of lithium-ion supply left. Therefore, if battery systems were to use lithium-ion, it is not a long-term solution. This leads to the last disadvantage i.e. the lifetime of the battery. The lifetime of a battery is limited. The more cycles of charge and discharge increase, and more chemical reactions take place within the battery, lead to physical changes within the battery, such as lower cell voltage as shown in Figure 3, reducing performance and its mechanical strength. [1]

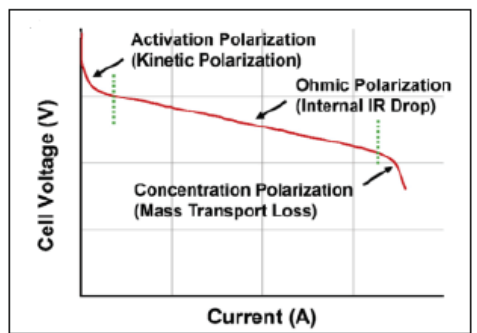

Figure 3 Variation of cell voltage induced by polarisations - [5]

\section{METHODOLGY}

\section{Overview}

A software package called HOMER, which stands for Hybrid Optimization Model for Multiple Energy Resources was used. The software was used to simulate battery storage systems using different technologies, an electrical demand profile for the selected home and solar renewable energy resource available in Sri Lanka. HOMER is a simulation model; the software attempts to simulate a viable system with different combinations of equipment that are considered using an optimization algorithm that finds the least-cost effective options for electrical distribution systems. HOMER also simulates a system or design and generates a set of results and specific sensitivity cases. From this, HOMER determines the optimum system from the data provided. HOMER energy claims there is no better software available on the market that compares to itself for renewable energy systems. It is a popular tool for simulating various renewable energy systems. HOMER has been used by various academics to model smallscale renewable energy systems such as optimizing solar PV systems or hybrid energy systems [16] [6]. Therefore, HOMER is a suitable option to model and simulate battery storage systems that are integrated into a renewable energy system to optimize a system at a low-cost. Thus, engineering technicality and economics are both considered alongside each other within this software.

\section{Locations for HOMER Simulations}

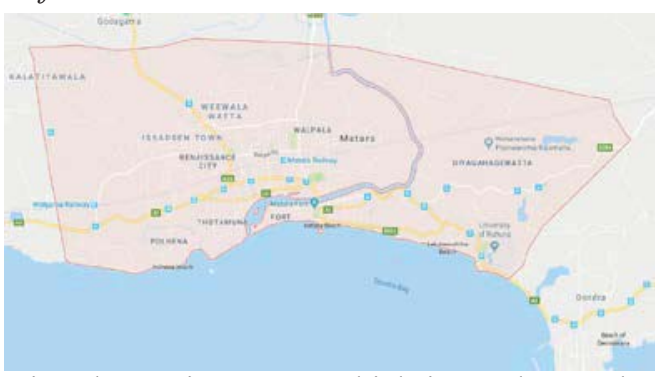

The city chosen is Matara which is on the southern coast of Sri Lanka. The city has a longitude and latitude of $5.9549^{\circ}$ North / $80.5550^{\circ}$ East (figure 29). The climate resources available such as temperature and solar radiation for Matara are displayed below in figures.

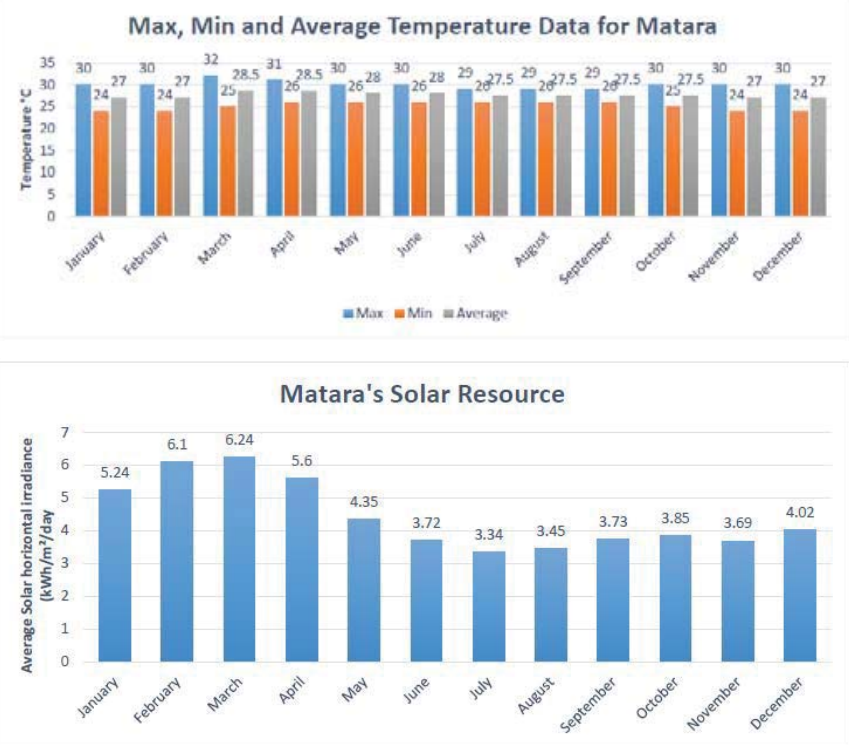

\section{Electricity Demand Profile}

For simulations in Sri Lanka, the daily $\mathrm{kWh}$ usage was estimated based on the literature. Therefore, the typical household energy use for a 3-bedroom home in Matara, Sri Lanka, was estimated to be around $7 \mathrm{kWh}$ per day with a peak power consumption of $1.5 \mathrm{~kW}$. The demand data for the electrical load profile is crucial when simulating renewable energy systems in HOMER to determine the capacity required to meet demand.

\section{Economics of the Renewable Energy System}

PV System- The main goal of this thesis is to determine the feasibility of battery storage systems as well as the technical feasibility. Economics of such systems play a big role in whether the system is feasible, therefore, accurate pricing data was gathered for each technology as below. [21]

\begin{tabular}{|l|l|l|l|}
\hline Component & Size & Capitol Cost (£) & Lifetime \\
\hline PV Panel & $4 \mathrm{KWp}$ & 5000 & 20 \\
\hline Converter & $2.5 \mathrm{KW}$ & 600 & 15 \\
\hline
\end{tabular}


Electricity Price- For Sri Lanka, the domestic electricity billing is split into five different tariffs from 0-180 electricity units as shown in Figure 4. A report by [17] showed that the total electricity consumption in 2011 was $3893 \mathrm{GWh}$ and this accounted for $27 \%$ of the total electricity consumption in Sri Lanka.

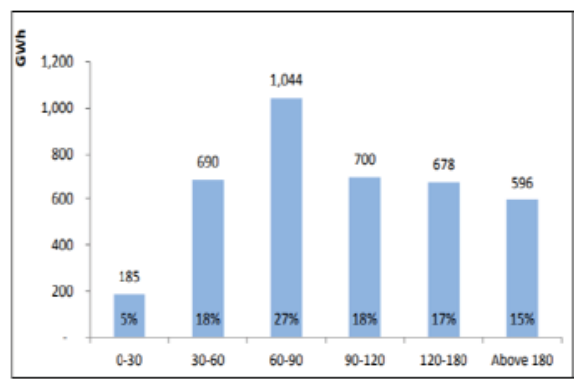

Figure 3 Sri Lanka's domestic electrcity tariffs.

In addition, Sri Lanka still relies heavily on fossil fuel for electricity consumption, with $53 \%$ coming from oil and coal thermal power stations and the rest from renewables $(12 \%)$ and $35 \%$ from hydro power [17]. Similarly, if the electricity consumption at a domestic level was covered by small renewable generation such as solar PV and wind, this combined with hydro could drastically reduce the need for fossil fuel-based plants.

TABLE I1 BATTERY ECONOMICS

\begin{tabular}{|c|c|c|c|c|}
\hline $\begin{array}{c}\text { Battery } \\
\text { Technology }\end{array}$ & $\begin{array}{c}\text { Type of } \\
\text { battery }\end{array}$ & $\begin{array}{c}\text { Useable } \\
\text { Capacity } \\
(\mathbf{k W h})\end{array}$ & $\begin{array}{c}\text { Price } \\
\mathbf{p e r} \\
\mathbf{k W h}(\mathfrak{f})\end{array}$ & $\begin{array}{c}\text { Total } \\
\mathbf{c o s t} \\
(\mathfrak{f})\end{array}$ \\
\hline $\begin{array}{c}\text { Tesla } \\
\text { Powerwall }\end{array}$ & Lithium-ion & 13.2 & 350 & 4850 \\
\hline LG Chem & Lithium-ion & 9.8 & 350 & 3500 \\
\hline GCL E-kwBe & Lithium-ion & 5.8 & 350 & 2500 \\
\hline $\begin{array}{c}\text { Trojan SIND } \\
\text { 04 2145 }\end{array}$ & Flooded/wet & 8.58 & 100 & 860 \\
\hline $\begin{array}{c}\text { Trojan SIND } \\
\text { 06 1225 }\end{array}$ & Flooded/wet & 7.35 & 100 & 735 \\
\hline $\begin{array}{c}\text { BAE PVS } \\
\text { 2470 }\end{array}$ & Tubular gel & 4.3 & 160 & 700 \\
\hline
\end{tabular}

Battery system- Lastly and most importantly is battery pricing. This determines the feasibility of implementing energy storage into a renewable energy system. Therefore, it is important that pricing data is as accurate as possible. When reading through literature on battery prices, many papers had different values but were roughly of the same vein. A paper written by [19] stated that current lithium-ion batteries used in solar storage in $2017 \mathrm{had}$ a cost of $350 \mathrm{f} / \mathrm{kWh}$. For lead acid batteries [18] states that currently, flooded/wet lead acid batteries have a cost of around $100 \mathrm{f} / \mathrm{kWh}$ and tubular gel lead acid batteries have a cost of around $160 £ / \mathrm{kWh}$. The price per $\mathrm{kWh}$ for each battery technology has been determined and is shown below in Table 2. The total price of the battery storage was acquired by multiplying the $\mathrm{kWh}$ price by the amount of energy storage capacity. [22][20]

\section{DESIGN THE SYSTEM}

\section{HOMER Simulations}

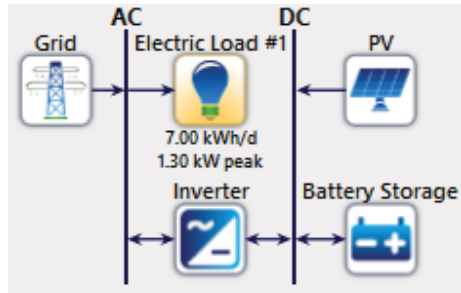

Using the HOMER software, simulations of the energy systems will be carried out on a typical 3-bedroom family home, located in Matara, Sri Lanka. Figure $\mathrm{x}$ shows the building block schematic diagram in HOMER when simulating a system. In this case, this is the block diagram for a PV system in Sri Lanka.

When creating the project in HOMER for Matara, the project lifetime was set at 20 years with an inflation rate of $2 \%$ and a discount rate of $8 \%$. Location was assessed for grid connected systems to optimize and determine the best suited technology. The renewable energy system was simulated with all 6 batteries, lithium-ion and lead acid batteries, with solar PV array of $3.1 \mathrm{kWp}$ for Matara, due to lower electrical load within the building. When carrying out the simulations, the results were displayed in 3 sections; firstly, the output results of the renewable generator, secondly the technical results which included the renewable fraction percentage, this is the energy delivered to the electrical load that originated from the renewable power source. Obviously, this is dependent on the renewable resource available. Other technical aspects included emissions, hours of autonomy, annual throughput of the battery, dispatch type and electrical production percentage, combined from both grid and renewable power sources. Lastly, the economic results were displayed showing the initial capital cost, operation and maintenance costs, grid interaction and the net present cost. Each of the parameters listed above are explained in more detail below.

Firstly, looking at the dispatch type, this is the way HOMER decides what the best combination of supplies are to meet the electric load. There are two types; these are load following and cycle charging. Under load following, the generators produce enough to serve the load. Under cycle charging, the generator (PV system) runs at full power and charges the battery with any excess electricity. Emissions of each system are calculated in terms of the average $\mathrm{CO}_{2}$ emissions produced by the grid that the system is connected to and the footprint of the technology used in the model. Battery autonomy in HOMER calculates this by dividing the usable nominal capacity of the battery bank (kWh) by the average primary load $(\mathrm{kW})$. The annual throughput of the battery is the amount of energy that is cycled through the battery bank in one year and is measured after charging losses and before discharging losses. This value is used to calculate the lifetime of the battery bank. The interaction with the grid in the simulations that are connected to the grid is a very important 
characteristic. It determines if the storage system is being used and is based on the money that can be saved by exporting electricity rather than storing the excess electricity in the battery. Operating and maintenance costs are based on the costs and revenues that are not included in the initial capital cost. In the models built and simulated, these costs include PV maintenance and replacement of batteries and any maintenance required on the batteries.

The present net cost of a system is the present value of all the costs of installing the equipment/technology and the ongoing cost of operating over a project lifetime of 20 years in this case. This cost is subtracted from the present value of all revenues that the system earns over the project lifetime. The costs that are included in the analysis are capital costs, replacement costs, operation and maintenance costs, fuel costs (for stand-alone systems that require a diesel generator), carbon tax, grid import costs and revenue gained from exporting electricity [20].

Each model is simulated in hourly-time steps and HOMER presents the optimum system for the best current net cost to be identified. This is displayed in the results section as shown in figure $\mathrm{x}$ of this thesis. Lastly, it is important to note that when simulating these models in HOMER and looking at the feasibility of a system, both technical and economic results are equally important when evaluating the feasibility of a suitable battery.

\section{RESULTS AND DISCUSSION}

\begin{tabular}{|c|c|}
\hline Rated Capacity & $3.1 \mathrm{kWp}$ \\
\hline Mean Output & $13.7 \mathrm{kWh} / \mathrm{d}$ \\
\hline Capacity Factor & $18.4 \%$ \\
\hline Annual Production & $4990 . \mathrm{kWh} / \mathrm{yr}$ \\
\hline
\end{tabular}

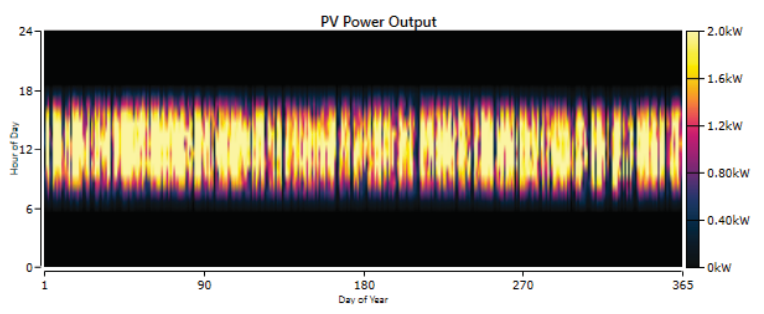

Figure 4 Matara Solar PV Output during the year.(HOMER)

There was a remarkable PV output generated in Matara simulation, which was $4,990 \mathrm{kWh}$ with a capacity factor of $18.4 \%$. Figure 4 shows the PV output was high throughout the year because of Matara's geographical location. This area has consistent sun resources, leading to consistent solar PV output throughout the year. Accordingly, as shown in Figure 4, due to the excellent solar resource, (achieving between 90-100\% renewable fraction with solar PV + battery storage), this house relied very little on the grid due to the lower electrical load needed. The technical and economic results from HOMER simulations presented in Table 3 and Figure 5 shows the HOMER state of charge results from relative batteries used for the research work.
TABLE I1I HOMER TECHNICAL \& ECONOMIC RESULTS FOR GRID CONNECTED SOLAR PV SYSTEM IN MATARA

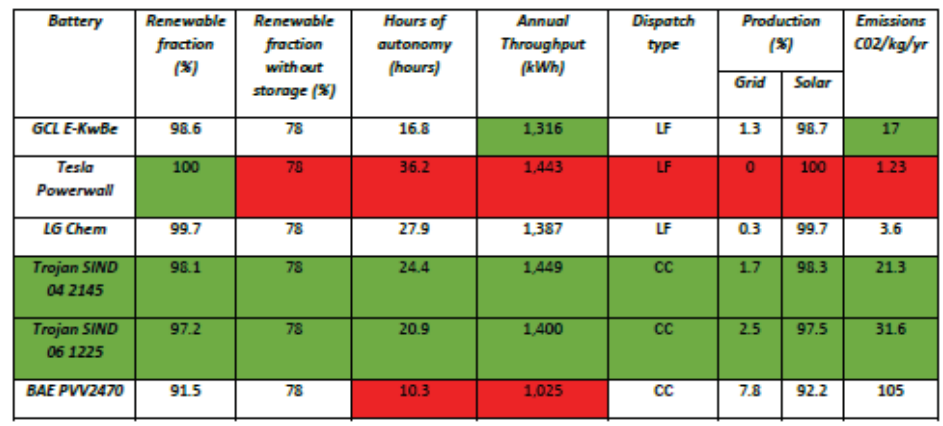

\begin{tabular}{|c|c|c|c|c|c|}
\hline \multirow[t]{2}{*}{ Battery } & \multirow[t]{2}{*}{ Initial capital cost (f) } & \multirow{2}{*}{$\begin{array}{l}\text { Operation and } \\
\text { maintenance (f) }\end{array}$} & \multicolumn{2}{|c|}{ Grid interaction $k W h / y r$} & \multirow[t]{2}{*}{ Net present Cost (f) } \\
\hline & & & Import & Export & \\
\hline GCLE-Kwbe & 7,410 & 40.4 & 68 & 2,268 & 7,816 \\
\hline Tesla Powerwall & 9.804 & $\overline{157.1}$ & 5 & 2.002 & 11.625 \\
\hline L6 Chem & 8,383 & 82.3 & 14 & 2,185 & 9,337 \\
\hline Trojan SIND 042145 & 5,118 & 46.7 & 85 & 1,901 & 5,661 \\
\hline Trojan SIND 061225 & 4,994 & 65.6 & 126 & 1,925 & 5,760 \\
\hline BAE PVV2 2470 & 4,960 & 154.3 & 418 & 2,380 & 6,785 \\
\hline
\end{tabular}

In this simulation all the suggested batteries used throughout the year are shown by the "state of charge" graphs presented. This is further illustrated by the renewable fraction value which is around $20 \%$ lower for Matara when not using batteries, therefore proving that batteries can improve the amount of renewable energy used to meet the electrical load.
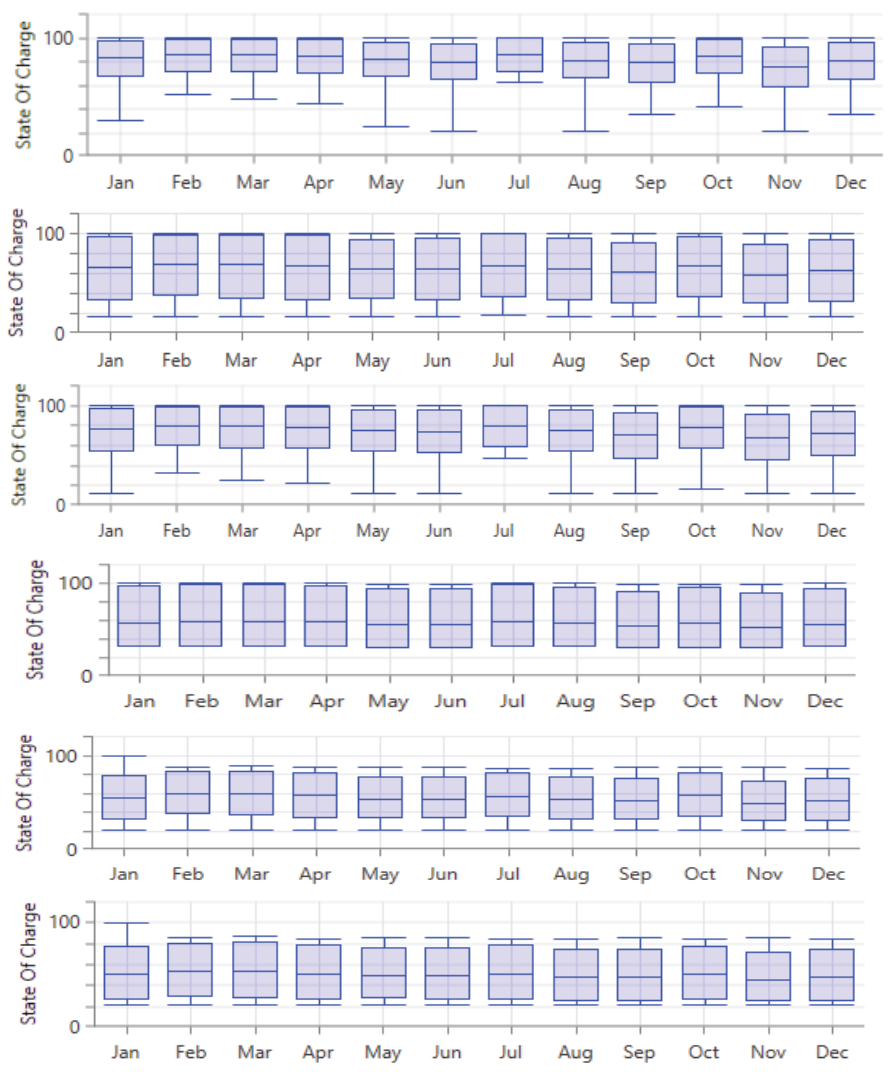

Figure 5 Tesla Powerawall, LG Chem, GCL E-KwBe, BAE PVS 2470, SIND 061225 \& SIND 042145 state of charge with grid connected PV system in Matara 
All the batteries, apart from the tesla Powerwall seem to fully charge and discharge, utilizing full capacity storage. The reason that the tesla Powerwall only discharges by around $30 \%$ from $100 \%$ is because of its high storage capacity of 13.2 $\mathrm{kWh}$. The identified household has a low energy consumption. Therefore, even though the performance is great from the tesla Powerwall, it still has the lowest operation costs as it does not import as much electricity from the grid as the other batteries.

However, it does not make sense as a lot of its storage capacity is being wasted or not utilized. LG Chem and BAE PVS 2470 batteries are shown to be fully charged and discharged to $20 \%$ as seen in figure. The batteries go through a full charge cycle, as mentioned previously, and this is a healthy option for the batteries, maximizing their lifetime operations and number of cycles.

Therefore, the economic and technical choice would be for the flooded lead-acid batteries as they roughly halve the initial capital cost and current net cost of the system. Lithium-ion batteries are not the best option for use in Matara. This is apparent when looking at the export and import rates as leadacid batteries import far more electricity from the grid.

\section{CONCLUSION}

This project studied the feasibility of domestic scale battery storage systems integrated with renewable energy technologies. It became evident very quickly that such systems with an energy storage device, such as a rechargeable battery, had high potential and could help to solve many of the current issues faced today by using renewable and sustainable technologies such as wind and solar that are intermittent resources. However, they also come with their disadvantage; mainly the high capital costs associated with them and some environmental concerns due to the mining of lithium-ion. Despite this, battery storage technology is a promising option for reducing the need for conventional power stations and reducing major environmental impacts that come with burning fossil fuels.

This is being researched by looking at new technologies that control the batteries to help them decide what to do and what would be the best economic options and "smart" electrical appliances. The behaviour patterns of consumers are very important and are taken into consideration when looking at battery storage usage at a domestic level.

According to results found, it was clear that Matara had a superior solar resource and used a grid-connected solar PV system and batteries storage.

The lithium-ion batteries, namely the Tesla Powerwall, were found not to be feasible due to the large storage capacity of $13.2 \mathrm{kWh}$ which was not utilized due to the lower electrical demand of the dwelling. Therefore, it was concluded that the best batteries to use with solar PV in Matara were; Trojan SIND 042145 or Trojan SIND 061225 lead-acid batteries. Both these batteries had a similar technical performance as the lithium-ion batteries but with a lower net present cost. This was mainly due to the lower electrical load demand.
When looking at the grid-connected system simulations, the results from this thesis are not exhaustive, as there are many other aspects that are not included in the HOMER calculations. For example, it does not consider the Feed in Tariff (FIT) revenue for small-scale renewable generation incentives in Sri Lanka. These extra revenues could increase the feasibility of such systems depending on the location in which they are deployed.

\section{REFERENCE}

[1] Akinyele D, "Battery Storage Technologies for Electrical Applications: Impact in Stand-Alone Photovoltaic Systems". energies, pp. 1-40,2017.

[2] Burheim. O. S, "Energy Storage. In: Engineering Energy Storage". London: Academic Press, pp. 1-14, 2017

[3] Halvarsson. P, "Grid connection of Renewable Energy," NA: ABB. 2012

[4] Hunt.T, "Is There Enough Lithium to Maintain the Growth of the Lithium-Ion Battery Market?", 2015 [Online] Available at: https://www.greentechmedia.com/articles/read/is-there-enough-lithiumto-maintain-the-growth-of-the-lithium-ion-battery-m\#gs. T=V=AgE

[5] Jaephil Cho, S. J, 2015. "Commercial and research battery technologies for electrical energy storage applications". Progress in Energy and Combustion Science, pp. 84-101, 2015

[6] Kaldellis. J. K, "Overview of stand-alone and hybrid wind. In: StandAlone and Hybrid Wind Energy Systems" Cambridge: Woodhead Publishing, pp. 1-13, 2010.

[7] Luo. X, "Overview of current development in electrical energy storage technologies and the application potential in power system operation" Applied Energy, pp. 511-536, 2014.

[8] MacKay. D. J, "Sustainable Energy Without the Hot Air". Cambridge: UIT Cambridge Ltd, 2010.

[9] Nattee Cheeweewattanakoon, G.K, "Residential Battery Energy Storage Systems (BESS) Modeling and Effect on". Indianapolis, IN, ASEE, pp. 1-16, 2014.

[10] Nirmal-Kumar C, Nair. N, "Battery energy storage systems: Assessment for small-scale renewable energy integration". Energy and Buildings, pp. 2124-2130, 2010.

[11] Nugent.D, "Assessing the lifecycle greenhouse gas emissions from solar PV”. Energy Policy, pp. 229-244, 2013.

[12] Peake. S, "Renewable Energy Power for a Sustainable Future". Oxford: Oxford University Press, 2017.

[13] REN21, "RENEWABLES 2018" GLOBAL STATUS REPORT, 2018

[14] Siraj Sabihuddin, A. E. K, "A Numerical and Graphical Review of Energy Storage Technologies" Energies, pp. 172-216, 2014.

[15] UNFCCC, "The Paris Agreement", 2016. [Online] Available at: http://unfccc.int/paris_agreement/items/9485.php

[16] Salam. M. A, "Optimal sizing of photovoltaic systems using HOMER for Sohar, Oman" INTERNATIONAL JOURNAL OF RENEWABLE ENERGY RESEARCH, pp. 302-306, 2013.

[17] Pucsl, "ELECTRICITY CONSUMPTION PATTERNS OF CONSUMERS IN SRI LANKA Marta" PUBLIC UTILITIES COMMISSION OF SRI LANKA, 2012.

[18] O'Connor. J. P, "Off Grid Solar: A Handbook for Photovoltaics with Lead-Acid or Lithium-Ion Batteries" New York: CreateSpace Independent Publishing Platform, 2016.

[19] Berckmans. G, "Cost Projection of State-of-the-Art Lithium-Ion Batteries for Electric Vehicles Up to 2030”. Energies, pp. 1-20, 2017

[20] HOMER, "HOMER PRO", 2018 [Online] Available at: https://www.homerenergy.com/products/pro/index.html

[21] SMA, "SUNNY BOY $1.5 / 2.5 ", 2018$. [Online] Available at: https://www.sma.de/en/products/solarinverters/sunny-boy-15-25.htm

[22] TESLA, "Meet Powerwall, your home battery", 2015. [Online] Available at: https://www.tesla.com/en GB/powerwall 